\title{
Homogeneous and heterogeneous reactions of phenanthrene with ozone
}

\author{
Yang Zhang, Bo Yang, Junwang Meng, Shaokai Gao, Xinyu Dong, Jinian Shu* \\ Research Center for Eco-Environmental Sciences, Chinese Academy of Sciences, Beijing 100085, China
}

\section{A R T I C L E I N F O}

\section{Article history:}

Received 13 May 2009

Received in revised form

30 October 2009

Accepted 6 November 2009

\section{Keywords:}

Phenanthrene

Ozonation

Homogeneous reaction

Heterogeneous reaction

Aerosol mass spectrometer

\begin{abstract}
A B S T R A C T
The reactions of gas-phase phenanthrene and suspended phenanthrene particles with ozone were conducted in a 2001 chamber. The secondary organic aerosol formation was observed in the reaction of gas-phase phenanthrene with ozone and simultaneously the size distribution of the secondary organic aerosol was monitored with a scanning mobility particle sizer during the formation process. The particulate ozonation products from both reactions were analyzed with a vacuum ultraviolet photoionization aerosol time-of-flight mass spectrometer. 2,2'-Diformylbiphenyl was identified as the dominant product in both homogeneous and heterogeneous reactions of phenanthrene with ozone. GC/MS analysis of ozonation products of phenanthrene in glacial acetic acid was carried out for assigning time-of-flight mass spectra of reaction products formed in the homogeneous and heterogeneous reactions of phenanthrene with ozone.
\end{abstract}

(c) 2009 Elsevier Ltd. All rights reserved.

\section{Introduction}

The homogeneous reaction of gas-phase volatile organic compounds (VOCs) and heterogeneous reaction of surface-bound organics with atmospheric oxidants such as $\mathrm{OH}$ radicals, $\mathrm{NO}_{3}$ radicals, and $\mathrm{O}_{3}$ are important atmospheric chemistry processes in the troposphere. The secondary organic aerosol (SOA) that results from the homogeneous reactions of VOCs effects particle pollution directly (human health, visibility, light scattering, and light absorption) and indirectly (cloud and haze formation) (Chuong et al., 2004; Kanakidou et al., 2005; Ervens and Kreidenweis, 2007). The heterogeneous reactions of surface-bound organics alter the chemical composition and hence may change the hygroscopic and toxic properties of aerosols (Rudich, 2003).

Polycyclic aromatic compounds (PAHs) and their derivatives are mainly derived from incomplete combustion of organic compounds and fossil fuels (Herner et al., 2001; Emmenegger et al., 2005; Kou et al., 2008). Three- to four-ring PAHs are semi-volatile and these compounds partition between the gas and solid phases in the atmosphere (Sitaras et al., 2004). Five and more rings PAHs tend to be mainly associated with particles having size $<1 \mu \mathrm{m}$ (Kahan et al., 2006; Gross and Bertram, 2008; Pitts et al., 1980; Vione et al., 2004). These pollutants have received considerable research attention since they have mutagenic and carcinogenic effects on humans (Pitts et al., 1980; Kou et al., 2008). The oxidized PAH derivatives are more toxic than their parent compounds because hydrophilic molecules are

\footnotetext{
* Corresponding author. Tel.: +86 0106284 9508; fax: +86 01062923563 .

E-mail address: jshu@rcees.ac.cn (J. Shu).
}

more easily reabsorbed in the alveolus (Barring et al., 2002). Thus PAHs reactions with atmospheric oxidants have been reported in the literature. Homogeneous reactions of ozone and hydroxyl radicals with low molecular weight PAHs have been investigated (Kwok et al., 1994; Atkinson and Aschmann, 1988; Wang et al., 2007). Heterogeneous ozonation was also studied with PAHs associated with different organic and inorganic substrates, such as soot, fly ash, water droplets, etc. (Murray and Singh, 1997; Kamens et al., 1985; Raja and Valsaraj, 2006; Kwamena et al., 2004; Perraudin et al., 2007a,b; Beltran et al., 1995,, 1999; Kahan et al., 2006).

Three-ring member phenanthrene exists mainly in gas phase in ambient air (May and Wise, 1984; Niles and Tan, 1989; Arey et al., 1987; Helmig and Harger, 1994; Vasilakos et al., 2007) because of its high vapor pressure at room temperature $\left(1.6 \times 10^{-2} \mathrm{~Pa}, 298 \mathrm{~K}\right.$, Osborn and Douslin, 1975). Kinetic studies and product identifications of gas-phase phenanthrene reactions with atmospheric oxidants were carried out by many groups. Kwok et al. (1994) obtained rate constants for the gas-phase reactions of phenanthrene with $\mathrm{OH}$ radicals and $\mathrm{O}_{3}$. Helmig and Harger (1994) investigated the $\mathrm{OH}$ radical-initiated reaction of gas-phase phenanthrene and identified the reaction products by high-performance liquid chromatography. Wang et al. (2007) investigated the formation of 9,10-phenanthrenequinone from the reactions of gas-phase phenanthrene with $\mathrm{OH}$ radicals and ozone. Though there is relatively little particle-phase phenanthrene in the atmosphere, the heterogeneous reaction of phenanthrene is of significance in atmospheric chemistry due to the potential higher efficiency of the heterogeneous reaction. Perraudin et al. measured the pseudo-first and second order rate constants for the reactions of ozone with phenanthrene adsorbed on 
different types of particles (Perraudin et al., 2007b) and the identification of phenanthrene gas-surface heterogeneous ozonation products was also reported (Perraudin et al., 2007a).

This paper reports an investigation on the homogeneous and heterogeneous reactions of phenanthrene with ozone utilizing a vacuum ultraviolet photoionization time-of-flight aerosol mass spectrometer (VUV-ATOFMS). The reactions of gas and particulate phase phenanthrene with ozone were conducted under pseudofirst-order conditions. The SOA formation from the reaction of gas-phase phenanthrene with ozone was observed with a scanning mobility particle sizer. The time-of-flight mass spectra of the solid state ozonation products from reactions of gas and particulate phase phenanthrene with ozone were obtained with the VUV-ATOFMS. The main ozonation products were assigned via GC/MS analysis of ozonation products of phenanthrene in glacial acetic acid.

\section{Experimental section}

\subsection{Description of the instruments}

The schematic diagram of the experimental setup is shown in Fig. 1. The aerosol reaction chamber consists of a thin-walled open head stainless steel drum $(50 \mathrm{~cm}$ (outer diameter) $\times 60 \mathrm{~cm}$ (height)) and a thin Tedlar polyvinyl fluoride (PVF) film bag (50 cm (diameter) $\times 50 \mathrm{~cm}$ (length)). The flexible PVF bag is used to keep one atmospheric pressure in the aerosol reaction chamber. The volume of the chamber is $\sim 2001$ when the PVF bag is fully filled. A muffle fan is set at the bottom of the aerosol reaction chamber to ensure rapid and sufficient mixing of reactants. The concentrations of gas-phase phenanthrene were measured by a gas chromatograph with a flame ionization detection (GC-FID, East \& West Analytical Instruments, Inc., China), which was equipped with a coil of $30 \mathrm{~m} \times 0.25 \mathrm{~mm} \times 0.25 \mu \mathrm{m}$ fused silica capillary as a column. The particle size and number in the reaction chamber were measured using a scanning mobility particle sizer (SMPS, TSI 3080) equipped with a long differential mobility analyzer electrode (TSI 3081) and a condensation particle counter (CPC, TSI 3010). The organic particles were postulated to be spherical particles and its density was assumed to be $1.0 \mathrm{~g} \mathrm{~cm}^{-3}$. The mass concentrations of organic particles were calculated from the size distribution and the particle density. Ozone was produced by an ozone generator (Shandong NIPPON, China) with an oxygen stream of

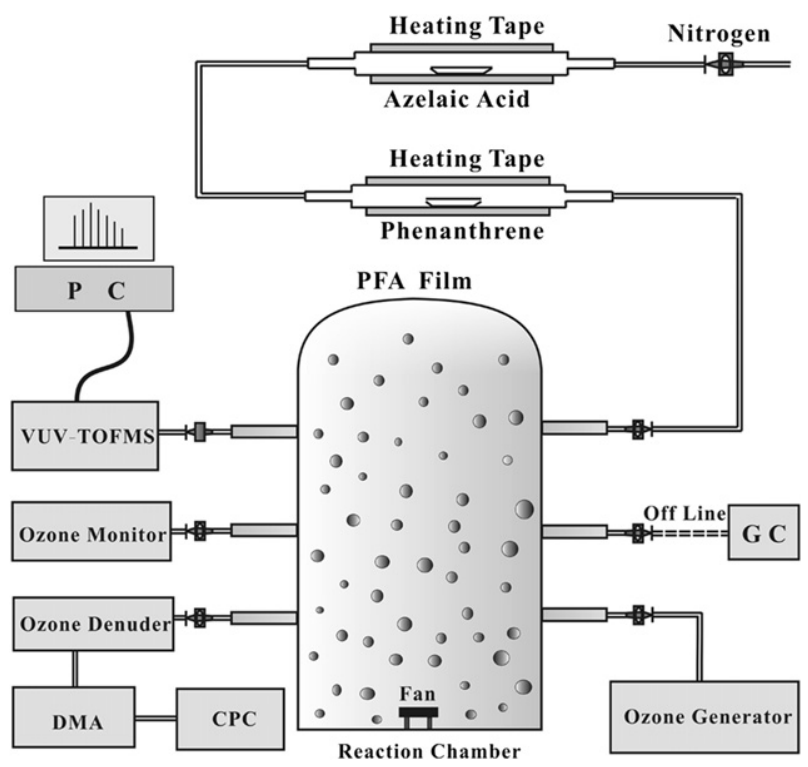

Fig. 1. Schematic diagram of the experimental setup.
$4.01 \mathrm{~min}^{-1}$. The concentration of ozone was measured with an ozone monitor (Model 202, 2B technologies Inc.). The aerosol reaction chamber was flushed with filtered air before each reaction experiment was carried out.

The VUV-ATOFMS utilized to analyze the chemical composition of particles in real-time is home-built and described in detail elsewhere (Shu et al., 2008). Therefore, only a brief description is presented here. A nozzle of $\sim 0.15 \mathrm{~mm}$ orifice combined with an aerodynamic lens assembly and a three stage differential pumping system is used to sample particles directly at a flow rate of $\sim 1.3 \mathrm{~cm}^{3} \mathrm{~atm} \mathrm{~s}-1$ under atmospheric pressure. The particles sampled are focused into a particle beam with a diameter of $\sim 1 \mathrm{~mm}$ by an aerodynamic lens assembly. An $8 \mathrm{~mm}$ diameter copper rod coupled with a cartridge heater placed in the detection chamber is used to vaporize the particles and the nascent vapor is photoionized with light radiated from a VUV lamp. The photon energy of the main output is $10 \mathrm{eV}$ (123.6 $\mathrm{nm}, \mathrm{Kr}$ atom resonance line) and the total photon flux output is about $5 \times 10^{14}$ photon $\mathrm{s}^{-1}$. The ions generated by VUV photoionization are then detected with a reflectron mass spectrometer with a field free flight distance of $1.4 \mathrm{~m}$, an ion mirror and a chevron multichannel plate detector.

\subsection{Homogeneous reaction experiment}

The phenanthrene vapor used for the homogeneous reaction was generated by heating $\sim 0.5 \mathrm{~g}$ of phenanthrene contained in a $3 \mathrm{~cm}$ (inner diameter) $\times 40 \mathrm{~cm}$ (length) quartz tube at $383 \pm 2 \mathrm{~K}$. The phenanthrene vapor was introduced into the chamber by flushing nitrogen at a constant flow rate of $1.01 \mathrm{~min}^{-1}$ controlled by a ball-float flowmeter. The introduction lasted $\sim 180 \mathrm{~min}$. The mass of the phenanthrene vapor introduced was $\sim 55 \mu \mathrm{g}$, which was estimated based on the GC-FID measurement of the same volume of nitrogen and phenanthrene vapor mixture prepared under the same conditions. Phenanthrene in the reaction chamber was collected by pumping the mixture through a filter containing resin (200 g Amberlite XAD-2 macroporous resin (Sigma-Aldrich)). The resin was extracted ultrasonically. The concentrated extract was measured with the GC-FID. Then ozone was added into the chamber and its initial concentration reached $\sim 23.50$ ppmv. The size distributions of the SOA particles were measured with the SMPS and the chemical composition of the SOA particles was analyzed with the VUV-ATOFMS.

\subsection{Heterogeneous reaction experiment}

The phenanthrene particles were generated by the homogeneous nucleation method. Two tandem $3 \mathrm{~cm}$ (outer diameter) $\times 40 \mathrm{~cm}$ (length) quartz tubes heated with heating tapes were used as an aerosol generator. Azelaic acid was chosen as the model nucleus because it was almost inert to ozone (Kwamena et al., 2007). A small ceramic container containing $\sim 0.4 \mathrm{~g}$ azelaic acid was positioned at the center of the first tube. A ball-float flowmeter was used to send a volumetric flow of $0.51 \mathrm{~min}^{-1}$ nitrogen through the first tube containing azelaic acid. The flow then passed through the second tube containing $\sim 0.4 \mathrm{~g}$ phenanthrene. The thickness of the phenanthrene coating was controlled by adjusting the temperature of the second tube. The temperature of two tubes was $413 \pm 2$ K. Fig. 2 shows the polydisperse size distributions of the generated particles measured with the SMPS. The size distribution of the pure azelaic acid particles has a mean diameter of $\sim 285 \mathrm{~nm}$ and the mass concentration of azelaic acid particles was $\sim 1530 \mu \mathrm{g} \mathrm{m}^{-3}$. The size distributions of the phenanthrene coated particles shifted to a mean diameter of $\sim 350 \mathrm{~nm}$ and the mass concentration was $\sim 2000 \mu \mathrm{g} \mathrm{m}^{-3}$. The mass of particulate phenanthrene was estimated roughly at $\sim 90 \mu \mathrm{g}$ in the reaction chamber. Ozone was introduced into the chamber and its 


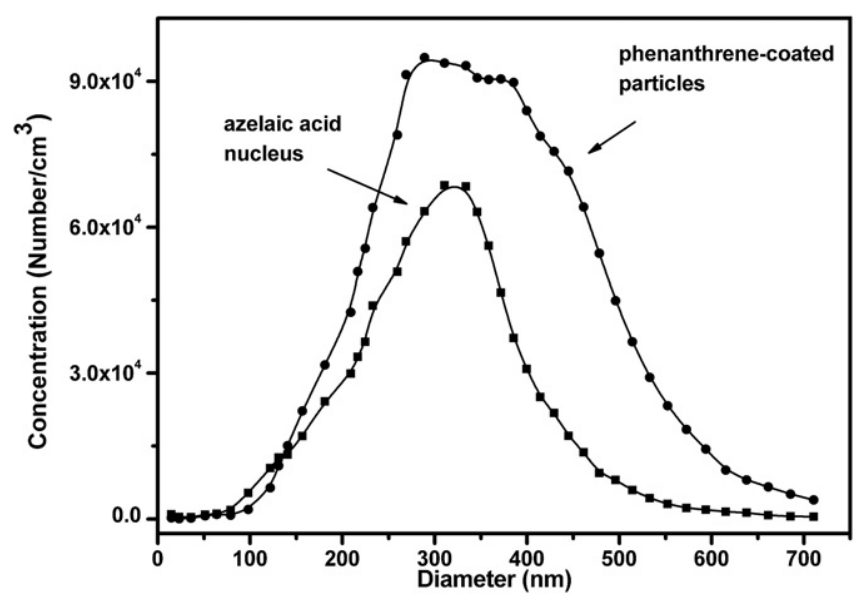

Fig. 2. Size distributions of the azelaic acid and phenanthrene particles.

initial concentration was $\sim 45.0 \mathrm{ppmv}$. The chemical compositions of the particles were analyzed in real-time with the VUV-ATOFMS.

\subsection{Liquid phase reaction}

In order to assign the time-of-flight mass spectra of the ozonation products of phenanthrene, GC/MS analysis of the ozonation products of phenanthrene in glacial acetic acid solution was carried out. A stream of oxygen containing $150 \mathrm{ppm}$ ozone with a flow rate of $1.51 \mathrm{~min}^{-1}$ bubbled through a beaker containing a solution of $200 \mathrm{mg}$ phenanthrene in $50 \mathrm{ml}$ glacial acetic acid. The bubbling took $20 \mathrm{~min}$. Then, the droplets generated by directly atomizing the solution were analyzed with the VUV-ATOFMS. $1.5 \mathrm{ml}$ ozonized solution was placed in one test tube and then dried in a nitrogen stream. The residuals in the test tube were dissolved with dichloromethane. The reaction products in dichloromethane solution were analyzed with a GC/MS. The GC/MS is a commercial product purchased from Agilent Technologies, which comprises a Hewlett-Packard (HP) 6890 gas chromatograph equipped with a $30 \mathrm{~m} \times 0.25 \mathrm{~mm} \times 0.25 \mu \mathrm{m}$ HP-5 capillary and an HP-5973 quadrupole mass filter with a $70 \mathrm{eV}$ electron impact ionizer. The chromatography conditions were the same as the literature (Perraudin et al., 2007a). The products were identified by comparing the EI mass spectra of the reaction products with those from the library mass spectra (NIST mass search, version 2005).

\subsection{Chemicals}

Phenanthrene (Acros, 97\%), azelaic acid (China North Region Special Chemical Reagent Development Center, 99\%), and glacial acetic acid (Beijing Chemical Works, AR) were used in the experiment. Oxygen (99.99\%) and nitrogen (99.99\%) were purchased from Beijing Huayuan Gas Chemical Industry Co. Ltd.

\section{Results and discussion}

SOA formation was observed in the homogeneous reaction of gasphase phenanthrene with ozone. After filling the reaction chamber with $\sim 55 \mu \mathrm{g}$ phenanthrene vapor, the size distribution of aerosol in the chamber was monitored with the SMPS for about $1 \mathrm{~h}$. Then, $\sim 23.5$ ppmv ozone was injected into the chamber. There was a small amount of residual particles in the chamber before the ozone injection. After ozone was introduced into the chamber, the mass concentration of the particles increased rapidly and reached a maximum at $\sim 70 \mathrm{~min}$ and then decreased most probably due to wall loss and deposition. Fig. 3a shows the time-dependent mass concentrations of aerosol in
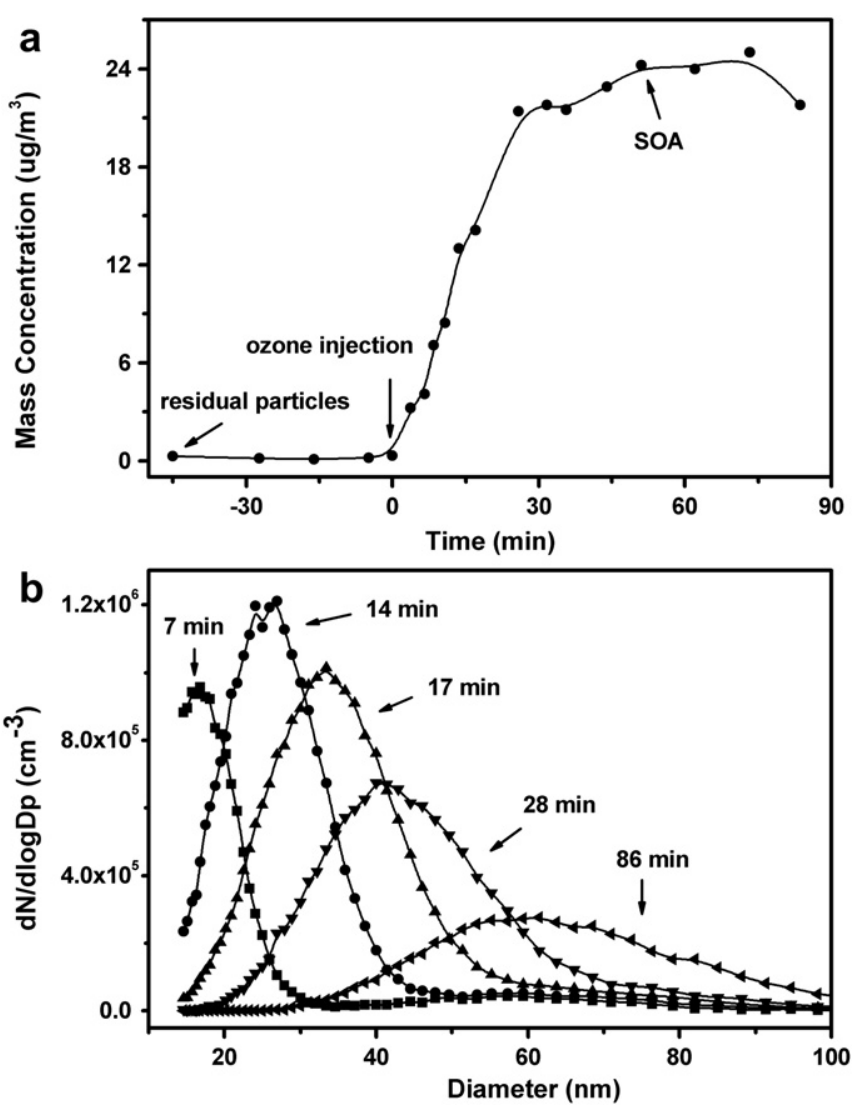

Fig. 3. a. Time-dependent mass concentrations of secondary aerosol particles resulting from the ozonation of phenanthrene vapor. b. The typical time-dependent size distributions of the secondary aerosol particles.

the chamber before and after ozone injection. The black dots in Fig. 3a stand for the mass concentrations of aerosol calculated with the size distributions and particle density. The typical time-dependant size distributions of the secondary aerosol particles are shown in Fig. 3b. The lines with squares, dots, up-triangles, down-triangles, and left-triangles show the size distributions of the particles measured 7 , $14,17,28$, and $86 \mathrm{~min}$ after the ozone injection. The size distributions of the secondary aerosol are polydisperse and the mean particle diameters shifts to a larger diameter with time. This phenomenon indicated the formation of SOA from the ozonation of phenanthrene vapor. The rough mean yield of the SOA during the first 25 min after the ozone injection is $\sim 18 \%$, which is derived from the reaction rate $k_{\mathrm{O}_{3}}=$ $4 \times 10^{-19} \mathrm{~cm}^{3} \mathrm{~mol}^{-1} \mathrm{~s}^{-1}$ for the gas-phase reaction of phenanthrene with ozone (Kwok et al., 1994).

The chemical composition of the SOA was analyzed with the VUV-ATOFMS and Fig. 4 shows the time-of-flight mass spectrum of the secondary aerosol particles. For the sake of convenient comparison, the background mass spectrum shown in Fig. 4a was acquired by sampling the phenanthrene vapor-filled chamber prior to ozone injection. The acquisition time was $200 \mathrm{~s}$. The mass peaks labeled $a$ and $b$ shown in Fig. 4a arise from mechanical pump oil vapor in the detection chamber of the ATOFMS, which is hard to remove even with the use of a liquid nitrogen trap in the detection chamber. The mass spectrum shown in Fig. 4b was acquired 36 min after ozone injection and normalized with the intensity of the mass peak at $m / z$ 181. The acquisition time was $500 \mathrm{~s}$. The dominant mass peak shown in Fig. 4 b is at $m / z 181$, which should correspond to the main product of the reaction. To assign this mass spectrum, we analyzed the ozonation products of phenanthrene in glacial acetic acid solution with the VUV-ATOFMS and GC/MS. Fig. 5a and b shows 


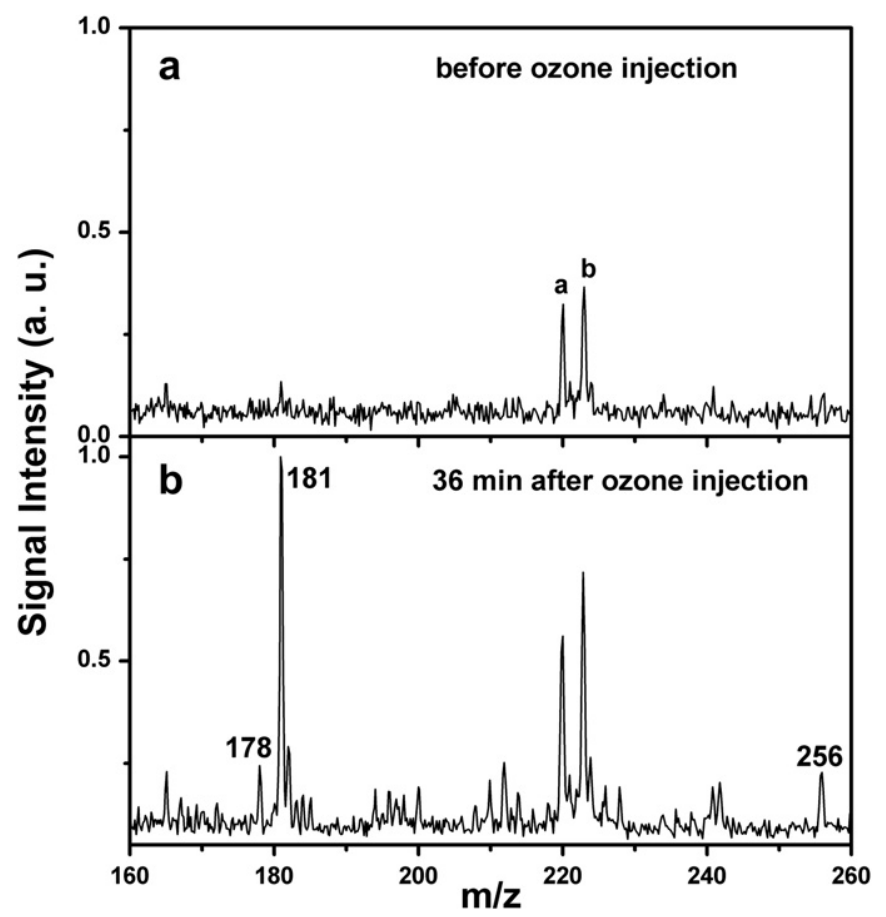

Fig. 4. Time-of-flight mass spectra of the ozonation products resulting from the reaction of phenanthrene vapor with ozone. The time-of-flight mass spectrum shown in Fig. 4a was acquired before ozone injection as a reference of the background and the acquisition time is $200 \mathrm{~s}$. The mass spectrum shown in Fig. 4b was acquired 36 min after ozone injection and the acquisition time is $500 \mathrm{~s}$.

the time-of-flight mass spectrum and the GC/MS total ion chromatogram of the ozonation products of phenanthrene in glacial acetic acid solution. The time-of-flight mass spectrum of the ozonation products of phenanthrene in glacial acetic acid solution shows mass peaks at $m / z 164,166,178,181,194,208,210$, and 253 . The mass peak at $m / z 178$ results from the molecular ion of phenanthrene. The mass peak at $m / z 181$ shown in Fig. 5a is the second strongest. The GC/MS total ion chromatogram in Fig. 5b shows a number of ion count peaks. However, apart from the peak of phenanthrene, only two of them can be identified with standard mass spectrum databases. One is the ion count peak with retention time at $23.2 \mathrm{~min}$, which is identified as $2,2^{\prime}$-diformylbiphenyl $\left(\mathrm{C}_{14} \mathrm{H}_{10} \mathrm{O}_{2}\right.$, mol. wt 210), the dominant reaction product. Another is the ion count peak with retention time at $25.2 \mathrm{~min}$, which is 9,10-phenanthrenequinone $\left(\mathrm{C}_{14} \mathrm{H}_{8} \mathrm{O}_{2}\right.$, mol. wt 208). 2,2'-Diformylbiphenyl was observed as the dominant ozonation product of phenanthrene by Perraudin et al. (2007a). Since the EI mass spectrum of the dominant reaction product $2,2^{\prime}$-diformylbiphenyl shows very strong fragment ion peak at $m / z 181$ and Fig. 5a also shows a strong mass peak at $m / z 181$, we assigned this peak shown in Fig. 4b to 2,2'-diformylbiphenyl and suggest it is the main reaction product of gas-phase phenanthrene. Other minor mass peaks shown in Fig. $4 \mathrm{~b}$ are not discussed in the paper due to the bad $\mathrm{S} / \mathrm{N}$ of the mass spectrum.

Fig. 6 shows the mass spectra of the ozonation products of phenanthrene particles. The mass spectrum shown in Fig. 6a was acquired right before ozone injection. The mass spectra shown in Fig. $6 \mathrm{~b}$ and c were respectively acquired 22 and $30 \mathrm{~min}$ after ozone injection. Each mass spectrum was collected in $100 \mathrm{~s}$. The mass spectra shown in Fig. 6 have been background subtracted and the intensity of the strongest mass peak of each mass spectrum is normalized to 1 . The mass peaks at $m / z 178$ and 179 shown in Fig. 6a arise from phenanthrene and ${ }^{13} \mathrm{C}$ phenanthrene. The mass peaks at $m / z 181,194,198$, $200,208,210,226$, and 256 shown in Fig. 6c arise from the major heterogeneous reaction products of particle-phase phenanthrene

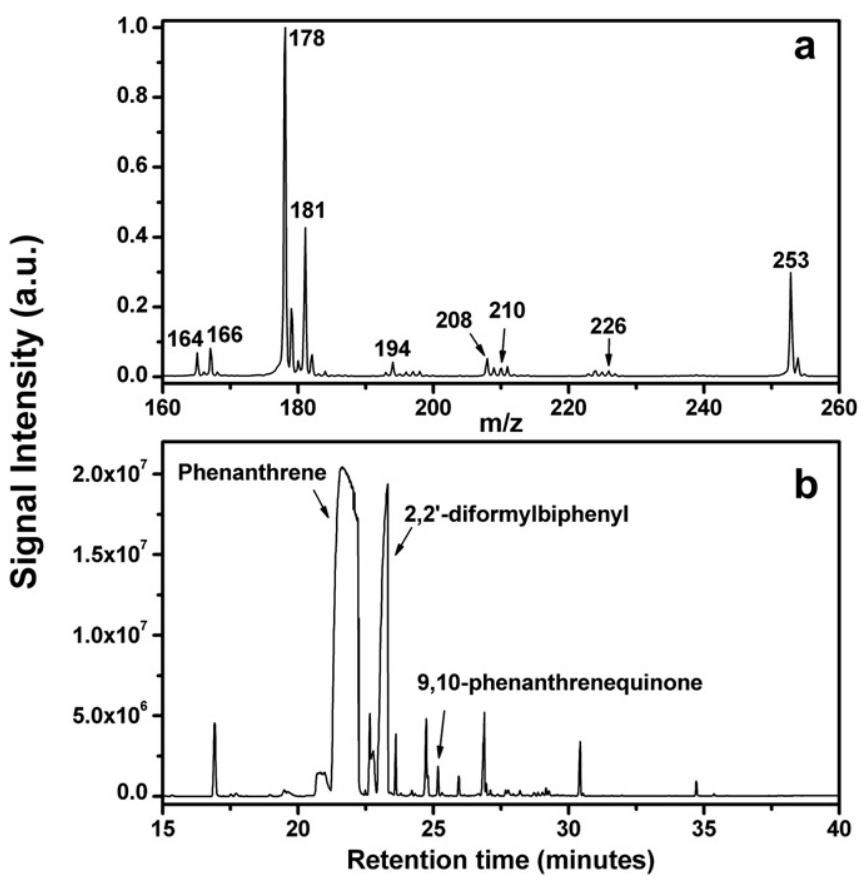

Fig. 5. Time-of-flight mass spectrum (a) and the GC/MS total ion chromatogram (b) of the ozonation products of phenanthrene in the glacial acetic acid solution.

with ozone. The dominant mass peak at $\mathrm{m} / \mathrm{z} 181$ was assigned to the daughter ion of 2,2'-diformylbiphenyl as discussed above. The mass peaks at 208 and 210 are assigned to the molecular ions of 9,10phenanthrenequinone $\left(\mathrm{C}_{14} \mathrm{H}_{8} \mathrm{O}_{2}\right.$, mol. wt 208) and 2,2'-diformylbiphenyl $\left(\mathrm{C}_{14} \mathrm{H}_{10} \mathrm{O}_{2}\right.$, mol. wt 210$)$ respectively based on the GC/MS analysis. The mass peaks at $m / z$ 194, 198, 226 are tentatively assigned to the molecular ions of 9-phenanthrol $\left(\mathrm{C}_{14} \mathrm{H}_{10} \mathrm{O}\right.$, mol. wt 194), 2'-hydroxy-biphenyl-2-carbaldehyde $\left(\mathrm{C}_{13} \mathrm{H}_{10} \mathrm{O}_{2}\right.$, mol. wt 198$)$, and 2(2-formylphenyl) benzoic acid $\left(\mathrm{C}_{14} \mathrm{H}_{10} \mathrm{O}_{3}\right.$, mol. wt 226) respectively by matching their $m / z$ to molecular weights of possible reaction products of phenanthrene. Other minor mass peaks may be contributed from secondary ozonation products. However, no chemical signatures can be found for them. The peak intensities and tentative assignments of these ozonation products are listed in Table 1.

It has been reported that ozone molecules preferentially attack the $9-10 \mathrm{C}-\mathrm{C}$ bond of the phenanthrene by a cycloaddition and $2,2^{\prime}-$ diformylbiphenyl is finally produced in the secondary reaction (Perraudin et al., 2007a; Schmitt et al., 1955). The reaction pathway of the phenanthrene initiated by the ozone attack on the 9-10 C-C double bond may be similar to the reaction pathway of alkene ozonation. The concerted cycloaddition of ozone to the $9-10$ bond produces a vibrationally excited primary ozonide, which results in the cleavage of one $\mathrm{O}-\mathrm{O}$ bond and the $9-10 \mathrm{C}-\mathrm{C}$ bond. Then, an unstable intermediate is formed, which is also called the Criegee intermediate $(\mathrm{CI})$. It is generally accepted that the formation of the Criegee intermediate occurs after ozone attacks the $9-10 \mathrm{C}-\mathrm{C}$ bond of phenanthrene. However, the mechanism for the subsequent fate of the Criegee intermediate is not very clear. $2,2^{\prime}$-Diformylbiphenyl was identified as the major products for both the homogeneous and heterogeneous ozonations of phenanthrene. The results were in agreement with the observation of the ozonation of PAHs absorbed on atmospheric model particles made by Perraudin et al. (2007a). 2,2'-Diformylbiphenyl may be formed by a sequence of reactions involving the hydrolysis of the Criegee intermediate (Perraudin et al., 2007a). Further oxidation of 2,2'-diformylbiphenyl may lead to the formation of 2-(2-formylphenyl) benzoic acid and 9,10-phenanthrenequinone (Raja and Valsaraj, 2006; Oconnor et al., 1957; Yao et al., 1998). 


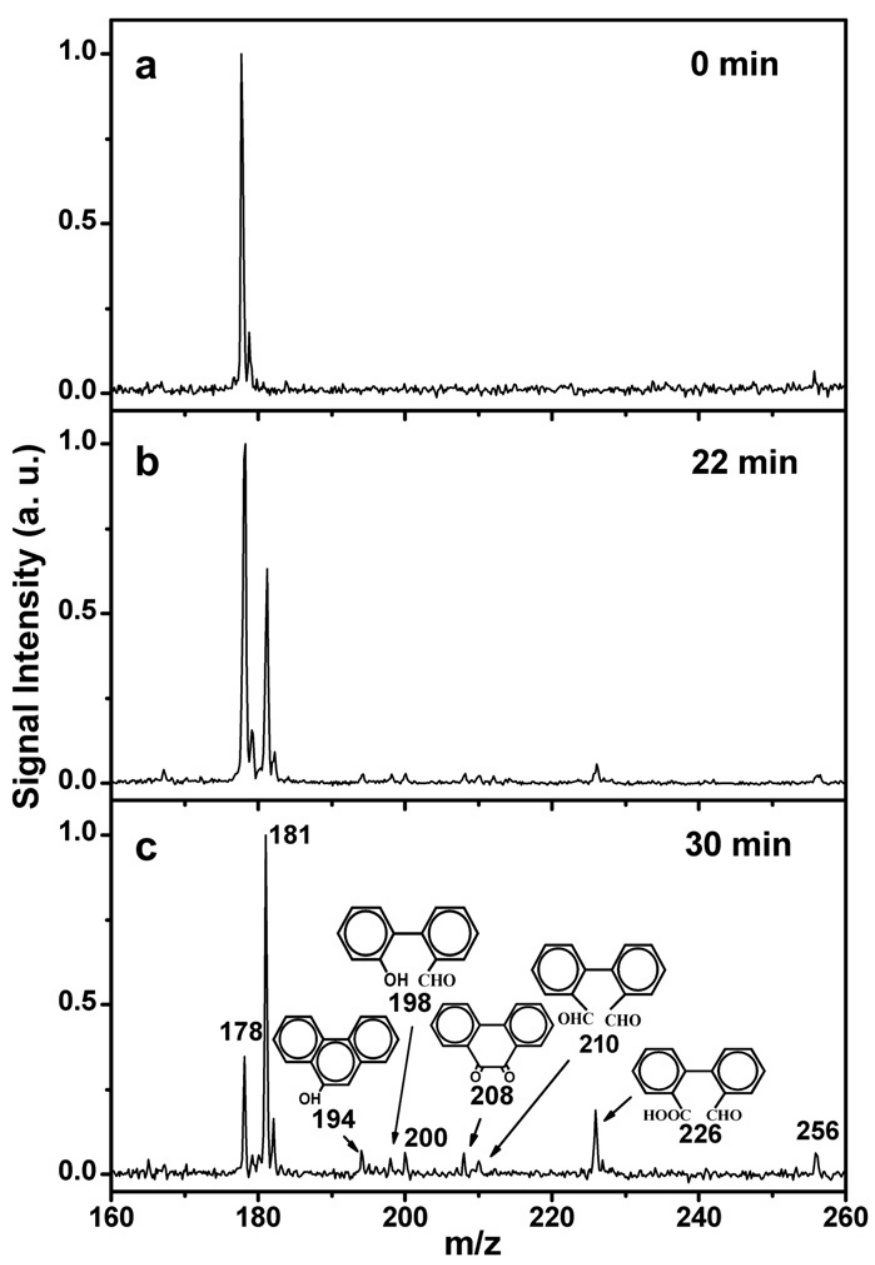

Fig. 6. Time-of-flight mass spectra of the ozonation products of particle-phase phenanthrene obtained before ozone injection (a); 22 min after ozone injection (b); and $30 \mathrm{~min}$ after ozone injection (c). The acquisition time for each spectrum is $100 \mathrm{~s}$.

9,10-Phenanthrenequinone was also observed by ozone reactions in gas-phase (Wang et al., 2007), on particles (Perraudin et al., 2007a), and in solution (Bailey, 1982). Since we are uncertain of the nature of the mechanism for the formation of the minor products 9phenanthrol and 2'-hydroxy-biphenyl-2-carbaldehyde, they are not discussed in the paper.

An attempt to assign the time-of-flight mass spectra of the reaction products of phenanthrene by collecting solid state products from ozonation of gas-phase phenanthrene was unsuccessful. Instead, GC/ MS analysis of the ozonation products of phenanthrene in glacial acetic acid solution was conducted. 2,2'-Diformylbiphenyl was identified as the main reaction product of phenanthrene in glacial acetic acid. It was also the dominant reaction product for both the homogeneous and heterogeneous reactions of phenanthrene with ozone. 9,10-Phenanthrenequinone was simultaneously identified. Other

Table 1

The major ozonation products of particle-phase phenanthrene.

\begin{tabular}{lll}
\hline$m / z$ & Tentative assignments & $\eta^{\mathrm{a}}$ \\
\hline 181 & 2,2'-Diformylbiphenyl & 1.00 \\
194 & 9-Phenanthrol & 0.07 \\
198 & 2'-Hydroxy-biphenyl-2-carbaldehyde & 0.05 \\
208 & $9,10-$-Phenanthrenequinone & 0.07 \\
226 & 2-(2-Formylphenyl) benzoic acid & 0.19 \\
\hline
\end{tabular}

${ }^{a} \eta$ represents the peak intensities of the major ozonation products from particlephase phenanthrene. reaction products were tentatively assigned. High concentrations of ozone and phenanthrene were used in the experiment to produce sufficient reaction products to meet the detection limit $\left(\sim 1 \mu \mathrm{g} \mathrm{m}^{-3}\right.$, PAHs) of the VUV-ATOFMS. It also needs to be mentioned that some homogeneous reaction of phenanthrene always occurs with the heterogeneous reaction of phenanthrene particulates due to the high vapor pressure of phenanthrene $\left(1.6 \times 10^{-2} \mathrm{~Pa}, 298 \mathrm{~K}\right)$. Since the signal from the ozonation of phenanthrene particles with a certain amount of phenanthrene vapor in the reaction chamber is ten times stronger than that from the homogeneous ozonation of pure phenanthrene vapor with ozone in the experiment, we speculate that time-of-flight mass spectra shown in Fig. 6 are mainly contributed from particlephase phenanthrene.

\section{Conclusion}

This paper reports an on-line investigation on the ozonation of gas and particle-phase phenanthrene in an aerosol reaction chamber with VUV-ATOFMS. The formation of the SOA resulting from the ozonation of gas-phase phenanthrene was observed. The reaction products from the gas and particle-phase phenanthrene were analyzed with the VUV-ATOFMS. GC/MS analysis of ozonation products of phenanthrene in glacial acetic acid was conducted for assigning the timeof-flight mass spectra of reaction products from the homogeneous and heterogeneous ozonation of phenanthrene. 2,2'-Diformylbiphenyl is observed as the dominant product for both the homogeneous and heterogeneous reactions of phenanthrene with ozone.

\section{Acknowledgment}

This research was funded by the National Natural Science Foundation of China (Grant No. 20673138 \& 20777082) and Creative Research Groups of China (Grant No. 50621804).

\section{References}

Arey, J., Zielinska, B., Atkinson, R., Winer, A.M., 1987. Polycyclic aromatic hydrocarbon and nitroarene concentrations in ambient air during a wintertime high-NOX episode in the Los-Angeles Basin. Atmospheric Environment 21, 1437-1444.

Atkinson, R., Aschmann, S.M., 1988. Kinetics of the reactions of acenaphthene and acenaphthylene and structurally-related aromatic-compounds with $\mathrm{OH}$ and $\mathrm{NO}_{3}$ radicals, $\mathrm{N}_{2} \mathrm{O}_{5}$ and $\mathrm{O}_{3}$ at $296 \pm 2 \mathrm{~K}$. International Journal of Chemical Kinetics 20, 513-539.

Bailey, P.S., 1982. Ozonation in Organic Chemistry Vol. II Nonolefenic Compounds. Academic Press, New York.

Barring, H., Bucheli, T.D., Broman, D., Gustasson, O., 2002. Soot-water distribution coefficients for polychlorinated dibenzo-p-dioxins, polychlorinated dibenzofurans and polybrominated diphenylethers determined with the soot cosolvencycolumn method. Chemosphere 49, 515-523.

Beltran, F.J., Ovejero, G., Encinar, J.M., Rivas, J., 1995. Oxidation of polynuclear aromatic-hydrocarbons in water.1. Ozonation Industrial \& Engineering Chemistry Research 34, 1596-1606.

Beltran, F.J., Rivas, J., Alvarez, P.M., Alonso, M.A., Acedo, B., 1999. A kinetic model for advanced oxidation processes of aromatic hydrocarbons in water: application to phenanthrene and nitrobenzene. Industrial \& Engineering Chemistry Research 38, 4189-4199.

Chuong, B., Zhang, J.Y., Donahue, N.M., 2004. Cycloalkene ozonolysis: collisionally mediated mechanistic branching. Journal of the American Chemical Society $126,12363-12373$.

Emmenegger, C., Kalberer, M., Samburova, V., Zenobi, R., 2005. High time resolution and size-segregated analysis of aerosol-bound polycyclic aromatic hydrocarbons. Environmental Science \& Technology 39, 4213-4219.

Ervens, B., Kreidenweis, S.M., 2007. SOA formation by biogenic and carbonyl compounds: data evaluation and application. Environmental Science \& Technology 41, 3904-3910.

Gross, S., Bertram, A.K., 2008. Reactive uptake of $\mathrm{NO}_{3}, \mathrm{~N}_{2} \mathrm{O}_{5}, \mathrm{NO}_{2}, \mathrm{HNO}_{3}$, and $\mathrm{O}_{3}$ on three types of polycyclic aromatic hydrocarbon surfaces. Journal of Physical Chemistry A 112, 3104-3113.

Helmig, D., Harger, W.P., 1994. OH radical-initiated gas-phase reaction-products of phenanthrene. Science of the Total Environment 148, 11-21.

Herner, H.A., Trosko, J.E., Masten, S.J., 2001. The epigenetic toxicity of pyrene and related ozonation byproducts containing an aldehyde functional group. Environmental Science \& Technology 35, 3576-3583. 
Kahan, T.F., Kwamena, N.O.A., Donaldson, D.J., 2006. Heterogeneous ozonation kinetics of polycyclic aromatic hydrocarbons on organic films. Atmospheric Environment 40, 3448-3459.

Kamens, R.M., Perry, J.M., Saucy, D.A., Bell, D.A., Newton, D.L., Brand, B., 1985. Factors which influences polycyclic aromatic hydrocarbon decomposition on wood smoke particles. Environment International 11,131-136.

Kanakidou, M., Seinfeld, J.H., Pandis, S.N., Barnes, I., Dentener, F.J., Facchini, M.C., Van Dingenen, R., Ervens, B., Nenes, A., Nielsen, C.J., Swietlicki, E., Putaud, J.P., Balkanski, Y., Fuzzi, S., Horth, J., Moortgat, G.K., Winterhalter, R., Myhre, C.E.L., Tsigaridis, K., Vignati, E., Stephanou, E.G., Wilson, J., 2005. Organic aerosol and global climate modelling: a review. Atmospheric Chemistry and Physics 5, 1053-1123.

Kou, J.H., Zhang, H.T., Yuan, Y.P., Li, Z.S., Wang, Y., Yu, T., Zou, Z.G., 2008. Efficient photodegradation of phenanthrene under visible light irradiation via photosensitized electron transfer. Journal of Physical Chemistry C 112, 4291-4296.

Kwamena, N.O.A., Staikova, M.G., Donaldson, D.J., George, I.J., Abbatt, J.P.D., 2007. Role of the aerosol substrate in the heterogeneous ozonation reactions of surface-bound PAHs. Journal of Physical Chemistry A 111, 11050-11058.

Kwamena, N.O.A., Thornton, J.A., Abbatt, J.P.D., 2004. Kinetics of surface-bound benzo[a]pyrene and ozone on solid organic and salt aerosols. Journal of Physical Chemistry A 108, 11626-11634.

Kwok, E.S.C., Harger, W.P., Arey, J., Atkinson, R., 1994. Reactions of gas-phase phenanthrene under simulated atmospheric conditions. Environmental Science \& Technology 28, 521-527.

May, W.E., Wise, S.A., 1984. Liquid-chromatographic determination of polycyclic aromatic-hydrocarbons in air particulate extracts. Analytical Chemistry 56, 225-232.

Murray, R.W., Singh, M., 1997. Activation of PAH by ozone derived oxidants: results using fly ash as particulate .1. Polycyclic Aromatic Compounds 12, 51-60.

Niles, R., Tan, Y.L., 1989. Determination of polynuclear aromatic-hydrocarbons and mononitrated derivatives in air and diesel particulates. Analytica Chimica Acta 221, 53-63.

Oconnor, W.F., Schmitt, W.J., Moriconi, E.J., 1957. Ozone oxidation of phenanthrene to diphenic. Industrial and Engineering Chemistry 49, 1701-1702.

Osborn, A.G., Douslin, D.R., 1975. Vapor-pressures and derived enthalpies of vaporization for some condensed-ring hydrocarbons. Journal of Chemical and Engineering Data 20, 229-231.
Perraudin, E., Budzinski, H., Villenave, E., 2007a. Identification and quantification of ozonation products of anthracene and phenanthrene adsorbed on silica particles. Atmospheric Environment 41, 6005-6017.

Perraudin, E., Budzinski, H., Villenave, E., 2007b. Kinetic study of the reactions of ozone with polycyclic aromatic hydrocarbons adsorbed on atmospheric model particles. Journal of Atmospheric Chemistry 56, 57-82.

Pitts, J.N., Lokensgard, D.M., Ripley, P.S., Vancauwenberghe, K.A., Vanvaeck, L., Shaffer, S.D., Thill, A.J., Belser, W.L., 1980. Atmospheric epoxidation of benzo [alpha]pyrene by ozone-formation of the metabolite benzo[alpha]pyrene-4,5oxide. Science 210, 1347-1349.

Raja, S., Valsaraj, K.T., 2006. On the reactive uptake of gaseous PAH molecules by micron-sized atmospheric water droplets. Atmospheric Research 81, 277-292.

Rudich, Y., 2003. Laboratory perspectives on the chemical transformations of organic matter in atmospheric particles. Chemical Reviews 103, 5097-5124.

Schmitt, W.J., Moriconi, E.J., Oconnor, W.F., 1955. The ozonolysis of phenanthrene. Journal of the American Chemical Society 77, 5640-5642.

Shu, J.N., Gao, S.K., Li, Y., 2008. A VUV photoionization aerosol time-of-flight mass spectrometer with a RF-powered VUV lamp for laboratory-based organic aerosol measurements. Aerosol Science and Technology 42, 110-113.

Sitaras, L.E., Bakeas, E.B., Siskos, P.A., 2004. Gas/particle partitioning of seven volatile polycyclic aromatic hydrocarbons in a heavy traffic urban area. Science of the Total Environment 327, 249-264.

Vasilakos, C., Levi, N., Maggos, T., Hatzianestis, J., Michopoulos, J., Helmis, C., 2007. Gas-particle concentration and characterization of sources of PAHs in the atmosphere of a suburban area in Athens, Greece. Journal of Hazardous Materials $140,45-51$

Vione, D., Barra, S., De Gennaro, G., De Rienzo, M., Gilardoni, S., Perrone, M.G. Pozzoli, L., 2004. Polycyclic aromatic hydrocarbons in the atmosphere: monitoring, sources, sinks and fate. II: sinks and fate. Annali Di Chimica 94, 257-268

Wang, L., Atkinson, R., Arey, J., 2007. Formation of 9,10-phenanthrenequinone by atmospheric gas-phase reactions of phenanthrene. Atmospheric Environment 41, 2025-2035

Yao, J.J., Huang, Z.H., Masten, S.J., 1998. The ozonation of pyrene: pathway and product identification. Water Research 32, 3001-3012. 